\title{
VIEWPOINT
}

\section{A Four-Letter Word in Medicine}

\author{
Elizabeth Cerceo
}

Cooper Medical School of Rowan University, Camden, NJ, USA.

Many approaches to burnout and compassion fatigue in medicine do not focus on the reason most physicians went into practice, namely love. And we do not explicitly think of our daily work in these terms. If we believe our job is to help others in a very task-oriented sense and we are not able to succeed or a patient has a poor outcome, we can miss the fact that often our simply being present is what is needed. Refocusing on our love of others in our work whether they are patients, colleagues, or administrators can reinvigorate our experience and make us happier people in the process.

J Gen Intern Med 34(11):2648

DOI: $10.1007 / \mathrm{s} 11606-019-05088-2$

(c) Society of General Internal Medicine 2019

$\mathrm{W}$ ith the upsurge in research on physician burnout, many have worried about how much we invest ourselves emotionally with our patients. What is the magic formula that prevents burnout, improves patient satisfaction, and increases productivity? There have been many creative solutions to this problem. Exposing left-brain scientist-physicians to the arts and humanities is one of the most popular and there are myriad courses and sessions using the arts to cultivate emotional depth and empathy. Narrative medicine places us in the position of telling a patient's story, not just their history and physical. The fine arts deepen our tolerance for ambiguity and expand our ability to take other perspectives. Mindfulness and meditation have been used as vehicles to create a peaceful state and deepen our appreciation of the workings of our mind.

There are many scales and psychometrics applied to the medical humanities that we hope will show to the community the importance of their presence in a curriculum. One can consider empathy, interpersonal and communication skills, cultural competence, and intellectual curiosity as some of the many facets of the question. Given the difficulty trying to translate the ineffable into a number, these scales are sometimes less than satisfying.

As valuable as all of these experiences are (and, as a director of the humanities at our medical school, I definitely value them), I think there is something more basic and fundamental that underlies all these individual qualities. Love.

Received January 30, 2018

Revised April 8, 2019

Accepted April 26, 2019

Published online August 26, 2019
It is probably not the first answer that people would give for why they became doctors. We may say we want to help others or we want to get others through illnesses but not necessarily that it is out of love. It is not a concept we are trained to embrace in our training. It is not a recognized strength. It is not necessarily measurable. And principles of love also have religious connotations that make scientific communities very uncomfortable. Without necessarily adhering to any one set of philosophies, love is universal and transcends the uniqueness of an individual's or a religion's belief system.

If many of us who have pursued a career in medicine considered it, we went into the field out of love for our fellow human beings who are all traveling with us on this journey. Ultimately, it is not the prestige or the money, the professional accolades, or the publications that bring fulfillment. It is love. The old adage that money does not buy happiness rings true in medicine.

Opening ourselves to the suffering of our patients and seeing them as unique, beautiful individuals allow us to connect with them, not as a healer and a patient but as two equals. True compassion lets us see our world and our patients with new eyes and it continually renews our energies so that, at the end of a busy day with sick patients in the hospital, we can still be invigorated and strengthened by our interactions with others. Even just keeping this word, love, in our mind as we approach a new patient changes our mental model for the interaction. It has the power to completely reframe our way of thinking. Remembering that we are doing this out of love can make the hours in front of the computer slightly less onerous and can make the extra time we spend seeing those added on patients go just a little faster.

The remedy to the problem of burnout in medicine may simply be a four-letter word: love.

Corresponding Author: Elizabeth Cerceo, Cooper Medical School of Rowan University, Camden, NJ, USA (e-mail: cerceoelizabeth@cooperhealth.edu).

\section{Compliance with Ethical Standards:}

Conflict of Interest: The author declares that she does not have a conflict of interest.

Publisher's Note Springer Nature remains neutral with regard to jurisdictional claims in published maps and institutional affiliations. 